\title{
A Practical Approach to Evaluating the Economic and Technical Feasibility of LED Luminaires
}

\author{
Sean Schmidt and Suzanna Long \\ Additional information is available at the end of the chapter
}

http://dx.doi.org/10.5772/66216

\begin{abstract}
LED roadway luminaires are currently under consideration for widespread implementation with departments of transportation, facilities managers, and city planners. This research focuses on a case study in Missouri and presents relevant research findings calculated by the authors as part of a project funded by the Missouri Department of Transportation. Although high-pressure sodium (HPS) luminaires have been the standard product for roadway illumination, advances in LED technologies have led many departments of transportation to consider them as viable options along state routes. For this case study, pilot sites were developed across the state of Missouri in sites assessed as moderately busy, medium pedestrian conflict zones. These zones were along roadways with an R3 pavement classification. This case study details the economic feasibility findings from the study; a life cycle cost approach was used. In addition, a technical feasibility analysis was conducted to determine fit with Illumination Engineering Society (IES) standards for the traffic pattern and pavement classification at study sites. Key findings reveal that LED roadway luminaires fail to outperform HPS in their current design, but may become technically and economically feasible in the future.
\end{abstract}

Keywords: LED roadway luminaires, life cycle cost evaluation, field data, energy consumption, environmental impacts

\section{Introduction}

As high-pressure sodium (HPS) roadway luminaires reach the end of their product life cycle, many states and local agencies, as well as city planners and utilities are considering LED roadway luminaires as a replacement product [1]. Manufacturers of LED luminaires promote their benefits as longer useful life, reduced operations and maintenance costs, reduced environmental impact, and reduced energy cost. This case study presents a quantitative method for 
assessing technical and economic feasibility of LED roadway luminaires for those considering the product for widespread implementation.

Previously, research has been completed on LED luminaires in the field case studies sponsored by the Department of Energy's Energy Efficiency and Renewable Energy (EERE) program [2]. Research has also shown the life cycle costs of LEDs may be higher than high-pressure sodium luminaires for both collector and local roads [3, 4]. The Illumination Engineering Society (IES) of North America standards for roadway illumination vary depending on three factors: classification of roadway, pedestrian conflict potential, and pavement classification. For example, if a roadway was classified as a moderately traveled major route with a low pedestrian conflict potential and an R3 pavement classification, then the minimum maintained average illumination would be 9.0 lux [5]. If the same roadway's pedestrian conflict potential was reclassified to be a high potential of pedestrian conflict, then the minimum maintained average illuminance increases to 17.0 lux. The Illinois Center for Transportation produced a report providing background information on LED luminaires [6]. This report covers optics of LED lighting, advantages and drawbacks of LED lighting, and summarizes work previously completed by several GATEWAY demonstrations.

Manufacturers, government agencies, and utilities are collaborating to produce effective LED roadway luminaires. One such effort is the Department of Energy's Solid-State lighting GATEWAY Demonstration programs, which investigate real-world application of solid-state lighting technologies in various fields, such as roadway illumination, sidewalk illumination, and parking lot illumination. These programs have performed feasibility analyses on several types of LED luminaires across several uses. Thus far, the program has published reports on the use of LED lighting in parking lot [7] and minor roadway lighting [8]. Research has previously been performed on combining an economic analysis with a product performance analysis to develop street lighting standards [9-12]. In addition, the benefits of LEDs have been investigated in a previous research, such as reduced concern of the power factor of electricity loads [13]. Another potential benefit is the ability to rapidly start luminaires without harmful impact on the luminaire's lifetime, which can allow for "smarter" usage of lighting systems [14].

The Missouri Department of Transportation commissioned research into the feasibility of replacing existing high-intensity-discharge roadway lighting with LED lighting luminaires. The goals of this research include a technical analysis on the ability of LED luminaires to meet the minimum performance standards set by the Illumination Engineering Society and an economic analysis to compare the life cycle costs of replacing existing lighting luminaires with LED luminaires.

\section{Evaluation of led roadway luminaires}

\subsection{LED luminaire data collection methodology}

Illumination readings were collected from LED luminaire testing sites throughout the state of Missouri. The luminaires studied are currently used on roadways throughout Missouri. These readings were collected for LEDs produced by several manufacturers at three HPS equivalent power ratings: 150, 250, and $400 \mathrm{~W}$. A total of eight unique manufacturer's LED luminaires were studied in this research. 
Data collection points are based on a function of the pole spacing between luminaires and the width of the traffic lane at the location of the luminaire. Using intervals of one quarter of the distance between the target pole and adjacent poles minimizes interference caused by nearby streetlights. The pole spacing, roadway width, the distance between the pole and the outer lane, and the location of the luminaire were measured, in feet, for each luminaire using a perambulator. In order to minimize the impact of nearby sources of light, illuminance readings were collected such that the readings were directed toward the target luminaire. An illuminance meter was used to measure the lux for each field data location. The illuminance meter is greatly impacted by the direction in which the eyelet of the device points. Therefore, in order to minimize error, the maximum reading was recorded for each data point. Data was collected in an interval based on illumination pole spacing, or the distance between two luminaires. Data was collected in intervals of $1 / 4$ of the pole spacing. Pole spacing varied between data collection sites. Perpendicular data collection intervals along the road were collected in intervals equal to one lane of traffic, which in most cases was approximately 12 feet (3.66 m).

Key characteristics for the field study are repeated from the final report of the funded MoDOT project [15]. For each luminaire, 31 readings, including 15 readings at the ground level and 15 readings elevated 18 inches above the ground level, were collected. In addition, field data includes one ambient reading collected from a nonilluminated area. Ambient illuminance readings were collected approximately 20 feet behind the luminaire in order to be outside of the illuminated area. In order to determine the role of naturally occurring light sources, ambient readings were collected. This includes ambient lighting from nearby outdoor area lighting. To calculate adjusted field readings, ambient readings were subtracted from the field readings. This was then compared to the ies file data for each studied luminaire. Figure 1

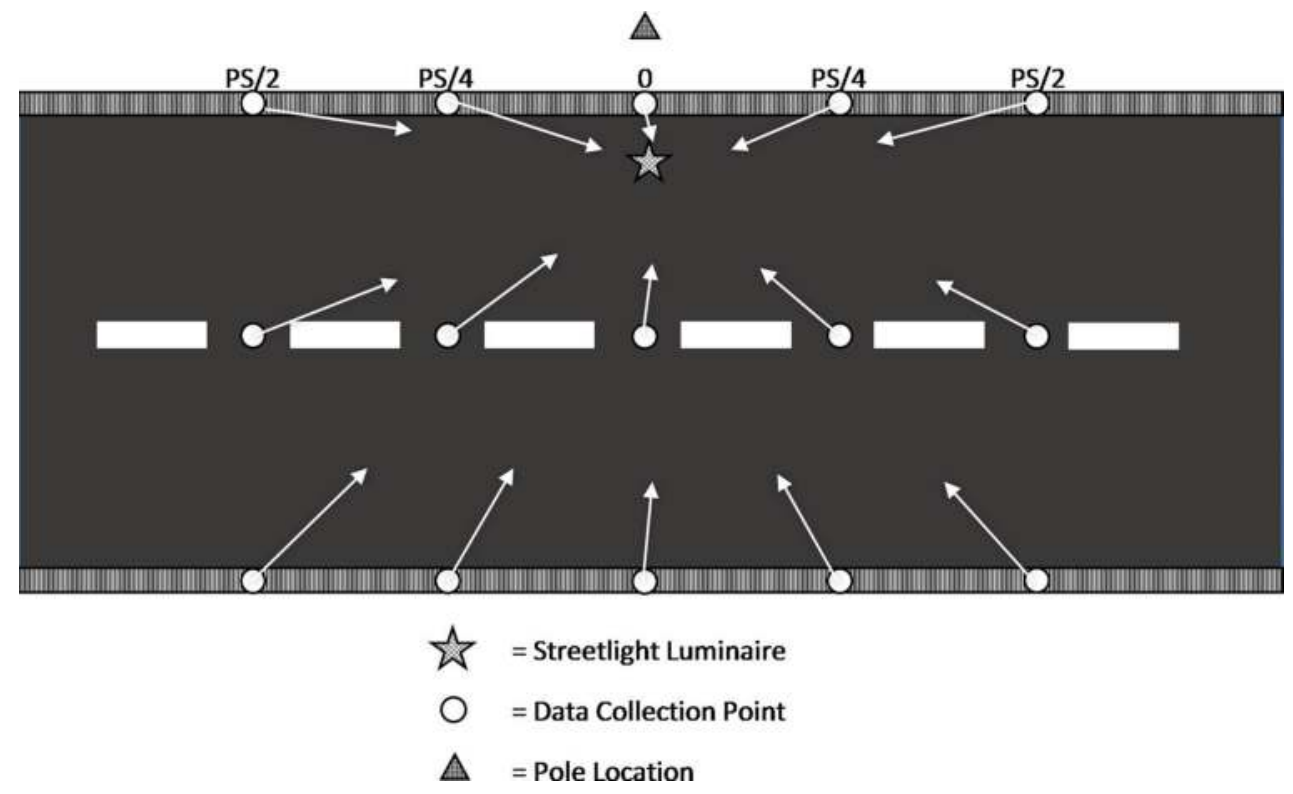

Figure 1. LED field testing methodology. 


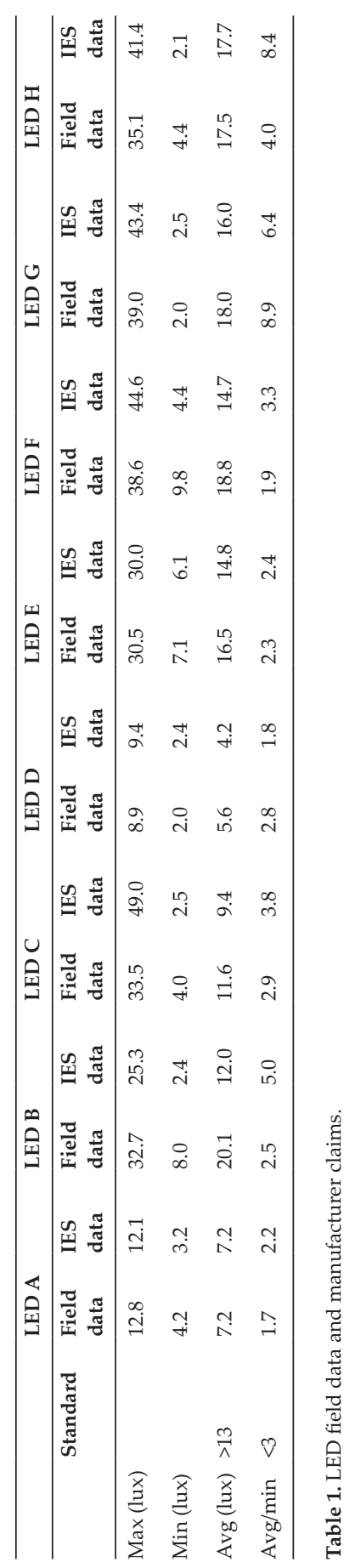


indicates the locations used for data collection points as well as the direction of the illuminance meter.

Once the field data collection phase ended, the manufacturer's .ies file for each luminaire was compared with field results to validate the manufacturer's claims. The variation between the field data and each manufacturer's claim was analyzed and is shown in figures within the field data evaluation and assessment section. Standards were created by the Illumination Engineering Society and are set in RP-08 [5]. These IES standards set a minimum of 13.0 lux for moderately busy, medium pedestrian conflict roads with R3 pavement classification. The desired average:minimum uniformity ratio for such a road is 3.0. Using the previously mentioned methodology, field data was collected for eight different LED luminaires across three HPS equivalent power ratings (150, 250, and $400 \mathrm{~W})$. Five 150, two 250, and one $400 \mathrm{~W}$ equivalent luminaires were studied in this research. All field data collected was then compared to the IES standards provided by the manufacturer and the average to minimum uniformity ratios were calculated in accordance to the IES RP-08 publication [5]. All tested luminaires were installed with 9 months of data collection, therefore light loss factors were not applied to collected illuminance values.

Four out of the eight luminaires met the minimum average illuminance criteria of 13.0 lux at 30 foot mounting heights for both field readings and manufacturer's claims. The field readings for LED B fulfilled the criteria for minimum average illuminance and average to minimum ratio, however, the manufacturer's provided ies file did not meet this claim, therefore LED B is deemed as technically infeasible. LEDs A, C, and D were deemed technically infeasible due to a combination of field readings and/or manufacturer's claims. LEDs F, G, and H were deemed technically infeasible due to their average to minimum ratios exceeding the 3.0 recommendation set by IES. The technical feasibility of HPS luminaires was not evaluated due to their current use in the transportation lighting field. LED fixtures were tested at mounting heights of 30 foot or less, since a significant portion of luminaires in Missouri is installed at these heights (Table 1).

\section{Economic feasibility analysis}

In order to conduct a thorough economic feasibility analysis of LED luminaires, several factors must be considered. These factors were originally reported in the MoDOT report and are repeated here [15]. Equivalencies are determined by grouping luminaires for comparison with the most appropriate high-pressure sodium luminaire. Manufacturers have worked to produce LED luminaires that are specifically designed as equivalent replacements for traditional high-intensity-discharge (HID) lamps. This allows transportation organizations the option of directly replacing traditional luminaires with LED luminaires, but other factors must be considered as well.

Second, the fiscal feasibility of LED luminaires rely heavily on the assumptions made pertaining to lifetime, labor hour cost, overhead, equipment costs, repair costs, discounts for ordering in large quantities, and electricity efficiency. The assumptions in this economic analysis include: 
replacing HPS luminaires after 3 years, LED luminaires remain in operation for 12 years, labor cost for relamping or retrofitting luminaires is $\$ 60$, and the costs for replacing high-pressure sodium lamps for 150,250 , and $400 \mathrm{~W}$ lamps are $\$ 100, \$ 130$, and $\$ 160$, respectively [15].

The economic analysis assumes high-pressure sodium luminaires are replaced every 3 years. This assumption can easily change to reflect a transportation agency's views of scheduling HPS replacements. The assumption of 3 years accounts for the reduction in luminaire lifetime due to vibration and shock, which is prevalent along bridges and overpasses, and spot replacement of HPS luminaires. In contrast, some transportation agencies wait until the HPS lamp fails catastrophically, which maximizes the lifetime of each luminaire.

Another key assumption is LED luminaires will remain in operation for a 12-year life expectancy. Many manufacturers claim the life of their luminaire will operate beyond 50,000 hours (approximately 12 years with an annual usage of approximately 4000 hours), however, the most common claim is a 12-year lifetime, and 12 years is a conservative lifetime overall for LED luminaires. Therefore, 12 years was used for the LED luminaire lifetime for the economic analysis.

Perspective on labor costs significantly affects the outcome of the economic analysis. Organizations that do not consider maintenance savings as a large factor to their organization will not likely find LED luminaires beneficial. For example, City Utilities in Springfield, $\mathrm{MO}$, replaces traditional street lighting technology on the downtime of their line workers. City Utility policy states that there must be line workers on duty 24 hours per day, 7 days per week in order to respond to outages and emergencies. Therefore, when City Utilities economically analyzed LED luminaires, the results did not favor LED luminaires because the avoided maintenance costs were not included in economic analysis. It is essential for each agency to consider their perspective on replacing or repairing luminaires when performing an economic analysis.

Labor cost to retrofit or relamp a light pole with an LED or an HPS luminaire was assumed to be $\$ 60$ per luminaire. With lighting labor costs around $\$ 25-\$ 35$ per hour, the labor cost was averaged and doubled to $\$ 60$ in order to account for overhead, equipment cost, setup, and travel time to estimate a conservative labor cost.

The costs for replacing high-pressure sodium luminaires vary by the wattage of the lamp being replaced. For the lowest wattage bulb, a $\$ 100$ cost is used which is based on related LED luminaire analyses. The costs of 250 and $400 \mathrm{~W}$ bulbs were estimated to be $\$ 130$ and $\$ 160$, respectively. The costs are based on the cost of the lamp being replaced, the cost of labor repairing the lamp's ballast, and the cost of vehicles and equipment to travel to and reach the luminaire.

As previously mentioned, costs may be reduced once roadway lighting demand shifts its focus solely toward LEDs. Economies of scale will then be realized, which similarly occurred in LED traffic signal indicators, and prices of LED luminaires will decrease significantly.

\subsection{Life cycle analysis}

To determine economic feasibility of LEDs, all costs to install, operate, and dispose of the luminaire are included in the analysis. The installation and disposal costs are accounted for in 
the retrofitting and relamping labor cost. In addition, the cost of powering the luminaire was calculated based on a sample of actual energy consumption. The actual energy consumption was then extrapolated to other luminaires based on relative wattages between the luminaires which energy consumption was known and other luminaires. Energy consumption for HPS luminaires was calculated using system wattages.

In order to make a fair comparison between HPS luminaires with assumed lifetimes of 3 years and LED luminaires with expected lifetimes of 12 years, the total cost to install and operate a luminaire was annualized. This allows for a fair economic comparison between products with varying lifetimes. An expected project return of 3\% was used to annualize costs.

Using information from Table 2-4, the annualized costs of LED luminaires is equivalent to or approaching equivalency to HPS lamps. This evaluation of the luminaires was based on pricing for small purchase orders, except for the manufacturer of LED E, which quoted a discounted price for orders of 1000 or more luminaires.

\subsection{Replacement period analysis}

A potential methodology to level the roadway lighting expenditures while transitioning from HPS luminaires to LED luminaires would be to slowly phase in LED luminaires. By transitioning to LEDs at a rate of the inverse of the expected lifetime of LED luminaires, the annual investment in LEDs is uniform. For example, if LEDs are rated to last for 12 years of use, then $1 / 12$ of lamps should be replaced with LEDs every year. This allows for approximately constant replacement of LED luminaires once the transition from HPS is completed because the failure rate of the LED luminaires will be evenly distributed throughout 12 years.

It is recommended to replace the LED luminaires in large, continuous sections. This will allow for more consistency in overhead street lighting for long sections of road. This will prevent the need to change between the high-pressure sodium and LED luminaires.

\begin{tabular}{lllllll}
\hline Life cycle analysis (150 W equivalents) & & & & & & \\
\hline Luminaire & $\mathbf{1 5 0 W}$ HPS & LED A & LED B & LED C & LED D & LED E \\
\hline Price & $\$ 100.00$ & $\$ 695.00$ & $\$ 695.00$ & $\$ 732.00$ & $\$ 700.00$ & $\$ 592.00$ \\
Expected lifetime (years) & 3 & 12 & 12 & 12 & 12 & 12 \\
Project rate of return & $3 \%$ & $3 \%$ & $3 \%$ & $3 \%$ & $3 \%$ & $3 \%$ \\
Pole installation costs & 0 & 0 & 0 & 0 & 0 & 0 \\
Relamping/retrofit labor costs & $\$ 60.00$ & $\$ 60.00$ & $\$ 60.00$ & $\$ 60.00$ & $\$ 60.00$ & $\$ 60.00$ \\
Initial cost per life cycle & $\$ 160.00$ & $\$ 755.00$ & $\$ 755.00$ & $\$ 792.00$ & $\$ 760.00$ & $\$ 652.00$ \\
Annual electricity consumption & $\$ 29.28$ & $\$ 26.91$ & $\$ 28.69$ & $\$ 29.36$ & $\$ 25.80$ & $\$ 32.03$ \\
Annualized cost & $\$ 85.84$ & $\$ 102.76$ & $\$ 104.54$ & $\$ 108.92$ & $\$ 102.15$ & $\$ 97.53$ \\
\hline
\end{tabular}

Table 2. Economic analysis of $150 \mathrm{~W}$ equivalent luminaires [15]. 


\begin{tabular}{llll}
\hline Life cycle analysis (250 W equivalents) & & \\
\hline Luminaire & $\mathbf{2 5 0 W}$ HPS & LEF F & LED G \\
\hline Price & $\$ 130.00$ & $\$ 700.00$ & $\$ 712.00$ \\
Expected lifetime (years) & 3 & 12 & 12 \\
Project rate of return & $3 \%$ & $3 \%$ & $3 \%$ \\
Pole installation costs & 0 & 0 & 0 \\
Relamping/retrofit labor costs & $\$ 60.00$ & $\$ 60.00$ & $\$ 60.00$ \\
Initial cost per life cycle & $\$ 190.00$ & $\$ 760.00$ & $\$ 772.00$ \\
Annual electricity consumption & $\$ 48.80$ & $\$ 40.26$ & $\$ 44.48$ \\
Annualized cost & $\$ 115.97$ & $\$ 116.61$ & $\$ 122.04$ \\
\hline
\end{tabular}

Table 3. Economic analysis of $250 \mathrm{~W}$ equivalent luminaires [15].

\begin{tabular}{lll}
\hline Life cycle analysis (400 W equivalents) & \\
\hline Luminaire & 400W HPS & LED H \\
\hline Price & $\$ 160.00$ & $\$ 800.00$ \\
Expected lifetime (years) & 3 & 12 \\
Project rate of return & $3 \%$ & $3 \%$ \\
Pole installation costs & 0 & 0 \\
Relamping/Retrofit labor costs & $\$ 60.00$ & $\$ 60.00$ \\
Initial cost per life cycle & $\$ 220.00$ & $\$ 860.00$ \\
Annual electricity consumption & $\$ 78.08$ & $\$ 66.72$ \\
Annualized cost & $\$ 155.86$ & $\$ 153.12$ \\
\hline
\end{tabular}

Table 4. Economic analysis of $400 \mathrm{~W}$ equivalent luminaires [15].

\subsection{Sensitivity analysis}

Figures 2 and 3 demonstrate the sensitivity of one LED luminaire and one HPS luminaire's annualized cost to changes of four variables: luminaire price, expected luminaire lifetime, relamping, retrofit labor cost, and annual electricity consumption. Each variable varies between 75 and $125 \%$ of the original value, in $12.5 \%$ intervals. The sensitivity analysis determined the variables with the greatest impact on the annualized cost of LED luminaires. In addition, an incremental economic analysis was performed. The results of the incremental analysis are displayed in Table 5. This analysis used the same values as the sensitivity analysis but calculated the change in annual worth per $1 \%$ change in each variable. Due to the nonlinearity of the expected lifetime variable, the incremental analysis results of this variable were averaged.

\subsection{Sensitivity analysis results}

The results of the sensitivity analyses in Figures 2 and 3 contrast the differences between HPS and LED luminaires as costs change. LED luminaires are significantly less sensitive to 


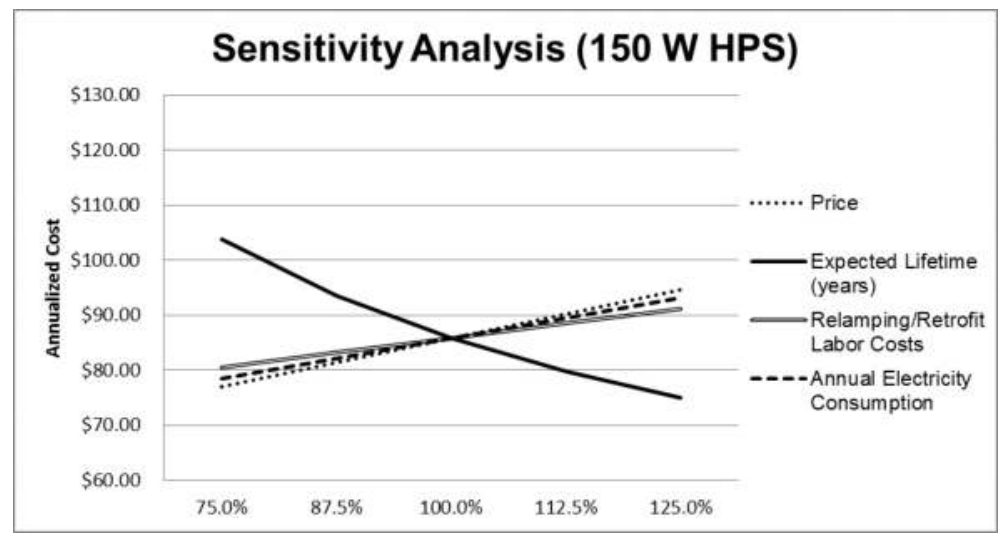

Figure 2. 150 W HPS sensitivity analysis.

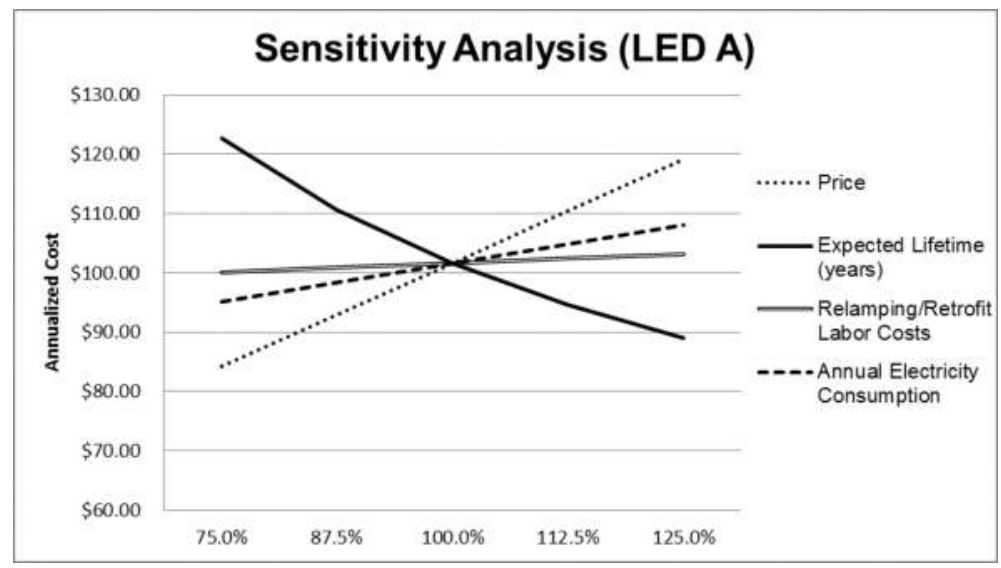

Figure 3. LED a sensitivity analysis.

changes in retrofitting costs, which consist mostly of labor costs. However, LED luminaires are significantly more sensitive to changes in the expected lifetime of the luminaire. Changes in the price of the luminaires linearly impact the annualized cost of the respective luminaire. Changes in each luminaire's expected lifetime result in an inverse exponential change in the annualized cost of the luminaire. Thus, the greater the deviation of the actual lifetime from the expected lifetime, the exponentially greater impact the life of the luminaire has on the annualized cost of the luminaire. Therefore, it is imperative for estimates of an LED luminaire's expected lifetime to be accurate.

The results of the economic sensitivity analysis show the change in annualized cost per $1 \%$ change in a variable value. For example, if the price of LED A decreased by $10 \%$, the annualized cost decreases by $\$ 7.00$. Due to the nonlinearity of the expected lifetime variable, the incremental sensitivity analysis was linearly approximated in order to compare results across 


\begin{tabular}{lllll}
\hline Incremental economic sensitivity analysis & & & \\
\hline Luminaire & Price & $\begin{array}{l}\text { Expected lifetime } \\
\text { (years) }\end{array}$ & $\begin{array}{l}\text { Relamping/Retrofit } \\
\text { labor costs }\end{array}$ & $\begin{array}{l}\text { Annual electricity } \\
\text { consumption }\end{array}$ \\
\hline 150 W HPS & $\$ 0.35$ & $(\$ 0.56)$ & $\$ 0.21$ & $\$ 0.29$ \\
LED A & $\$ 0.70$ & $(\$ 0.66)$ & $\$ 0.06$ & $\$ 0.27$ \\
LED B & $\$ 0.70$ & $(\$ 0.66)$ & $\$ 0.06$ & $\$ 0.29$ \\
LED C & $\$ 0.74$ & $(\$ 0.69)$ & $\$ 0.06$ & $\$ 0.29$ \\
LED D & $\$ 0.70$ & $(\$ 0.66)$ & $\$ 0.06$ & $\$ 0.26$ \\
LED E & $\$ 0.59$ & $(\$ 0.57)$ & $\$ 0.06$ & $\$ 0.32$ \\
250W HPS & $\$ 0.46$ & $(\$ 0.67)$ & $\$ 0.21$ & $\$ 0.49$ \\
LED F & $(\$ 0.66)$ & $\$ 0.06$ & $\$ 0.40$ \\
LED G & $\$ 0.70$ & $(\$ 0.67)$ & $\$ 0.06$ & $\$ 0.44$ \\
400W HPS & $\$ 0.72$ & $(\$ 0.77)$ & $\$ 0.21$ & $\$ 0.78$ \\
LED H & $\$ 0.57$ & $(\$ 0.75)$ & $\$ 0.06$ & $\$ 0.67$ \\
\hline
\end{tabular}

Table 5. Incremental sensitivity analysis of HPS and LED luminaires.

all variables. The results of the incremental analysis provide a starting point for effective estimation of annualized costs to account for changes in variable values.

\subsection{Energy consumption and environmental impact analysis}

Energy consumption data was obtained on a studied luminaire (LED A) at two separate intersections. Both intersections were located in St. Louis, MO. Energy consumption data was normalized to account for days in each month, hours of operation in each month, and the number of luminaires operated at each intersection. Energy consumption data was separated by month and analyzed. Figure 4 depicts the energy consumption in Watts per luminaire per month.

Figure 4 shows the increase in electricity consumption between October and December, which endures through the month of February. The increase in consumption at this time period averages to $32 \%$. This increase is independent of the duration which the lights operate. The approved product list process section suggests studying this effect further on more luminaires by assessing each luminaire during both summer and winter seasons.

The sharp decrease in March in consumption at the intersection of Route 30 and Main Drive is due to a traffic crash that removed the pole for a period of time. With no replacement LED in stock, one had to be ordered.

Energy consumption was also measured to determine the energy savings of LED luminaires. Our analysis shows an actual energy savings of $11 \%$, which is for $150 \mathrm{~W}$ equivalent luminaires. Information was unable to be obtained for equivalent LED power consumption data for $250 \mathrm{~W}$ or 400 watt HPS luminaires. 


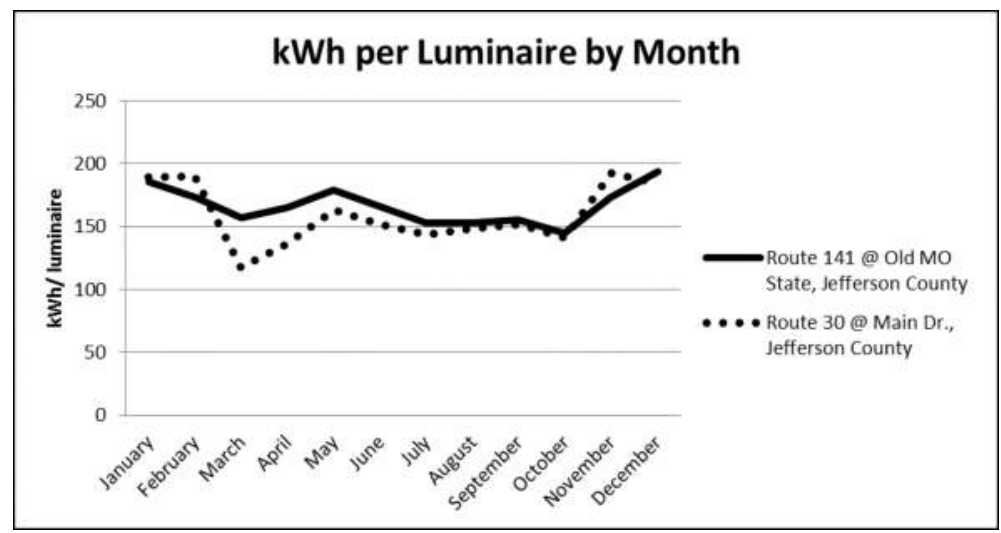

Figure 4. Electricity consumption per luminaire by month.

For a $150 \mathrm{~W}$ HPS lamp, with a system rating of 183 watts, the equivalent energy savings is 80.5 $\mathrm{kWh}$ per year. According to an EPA study from 2000, the average electrical generation portfolio releases $1.341 \mathrm{lbs}(0.608 \mathrm{~kg})$ of $\mathrm{CO}_{2}$ into the atmosphere per $\mathrm{kWh}$ of electricity consumed [16]. Therefore, replacing one 150 Watt HPS lamp with the LED A luminaire avoids the release of approximately $108 \mathrm{lbs}$ of $\mathrm{CO}_{2}$ into the atmosphere.

\section{Conclusions and future work}

Performance and cost are major issues when considering a change in technologies such as the transition to the use of LED roadway luminaires. Performance was a major issue in early development of LED roadway luminaires. Most manufacturers invested in product development to ensure that LED roadway luminaires performed at similar or higher performance levels as the HPS roadway luminaires. These initial investments were focused at 30-foot mounting height luminaires and have in the recent past moved toward mounting heights of 40 feet $(12.2 \mathrm{~m})$ or higher.

Performance of the LED roadway luminaire, when compared to the current preferred HPS roadway luminaire, has seen improvements over the past few years. Impacted parties (like manufacturers, public agencies, utilities, etc.) have joined together with the intent of producing an equivalent LED roadway luminaire that can be used. Manufacturers have invested in producing new generations of LED roadway luminaires that continue to close the gap between the HPS and LED roadway luminaire. Local agencies and utilities continue to evaluate and report findings on these new generations. Their performance improvements have led some agencies like the City of Los Angeles to make major investments in the transition to LED roadway luminaires.

Results from this research reveal that LED luminaires are less sensitive to changes in retrofitting costs (consisting mostly of labor costs). However, LED luminaires are more sensitive 
to changes in the expected lifetime of the luminaire. Changes in the price of the luminaires linearly impact the annualized cost of the respective luminaire and changes in each luminaire's expected lifetime result in an inverse exponential change in the annualized cost of the luminaire. Based on these findings, it is essential that life cycle costs for the lifetime of LED luminaires be as accurate as possible. Moreover, the economic sensitivity analysis reveals that incremental analysis provides an effective mechanism for estimating annualized cost.

Energy and environmental analysis shows promising results as well. For a 150-W HPS lamp, with a system rating of $183 \mathrm{~W}$, the equivalent energy savings is $80.5 \mathrm{kWh}$ per year. According to an EPA study from 2000, the average electrical generation portfolio releases $1.341 \mathrm{lbs}(0.608 \mathrm{~kg})$ of $\mathrm{CO}_{2}$ into the atmosphere per $\mathrm{kWh}$ of electricity consumed. Therefore, replacing one $150 \mathrm{~W}$ HPS lamp with the LED A luminaire avoids the release of approximately $108 \mathrm{lbs}$ of $\mathrm{CO}_{2}$ into the atmosphere.

Based on our analysis, LED luminaires are a promising technology for replacement of highpressure sodium lamps. As the technology matures, more robust analysis will confirm the efficacy of the approach.

\section{Acknowledgements}

This project was partially funded through the Missouri Department of Transportation (TRyy1101) and the data used in this case was originally published in the corresponding final report. The authors would like to thank Tom Ryan, Dr. A. Curt Elmore, and Dr. Ruwen Qin for their input and guidance throughout the research project. We also want to thank Julie Stotlemeyer and Jen Harper, MoDOT, for their valuable assistance.

\section{Author details}

Sean Schmidt and Suzanna Long*

*Address all correspondence to: longsuz@mst.edu

Department of Engineering Management and Systems Engineering, Missouri University of Science and Technology, Rolla, MO, USA

\section{References}

[1] LED Street Lighting Efficiency Program. Los Angeles: City of Los Angeles - Bureau of Street Lighting, 2011. http://bsl.lacity.org. Accessed December 2011.

[2] Pacific Northwest National Laboratory. Demonstration Assessment of Light-Emitting Diode (LED) Roadway Lighting. Washington D.C.: U.S. Department of Energy, 2009. 
[3] Radetsky LC. Specifier Reports: Streetlights for Collector Roads. Troy, Rensselaer Polytechnic Institute NY, 2010.

[4] Radetsky LC. Specifier Reports: Streetlights for Local Roads. Troy, Rensselaer Polytechnic Institute NY, 2011.

[5] Illumination Engineering Society. Roadway Lighting. Tech. No. RP-8-OOR2005. NY, 2000.

[6] Avrenli KA, Benekohal RF, Medina JC. LED Roadway Lighting. Urbana: University of Illinois at Urbana-Champaign, Department of Civil and Environmental Engineering, 2012.

[7] Pacific Northwest National Laboratory. Demonstration Assessment of Light-Emitting Diode (LED) Parking Lot Lighting. Washington D.C., U.S. Department of Energy 2011.

[8] Beckwith D, Zhang X, Smalley E, Chan L, Yand M. LED streetlight application assessment project. Transportation Research Record, 2011, pp. 65-75.

[9] Ellis RD, Amos SJ. Development of Work Zone Lighting standards for nighttime highway work. Transportation Research Record. 1996, pp. 35-42.

[10] Kostic M, Djokic L. Recommendations for energy efficient and visually acceptable street lighting. Energy. 2009; 34(10): pp. 1565-72.

[11] Kinzey BR, Royer MP, Hadjian M, Kauffman R. Demonstration of LED Street Lighting in Kansas City, MO. Washington D.C.; U.S. Department of Energy 2013.

[12] Pacific Northwest National Laboratory. LED Street Lighting. Washington D.C.; U.S. Department of Energy 2008.

[13] Gil-de-Castro A, Moreno-Munoz A, Larsson A, JJG de la Rosa, Bollen. LED street lighting: A power quality comparison among street light technologies. Lighting Research and Technology. 2013; 45: pp. 710-728.

[14] Pizutti S, Annunziato M, Moretti F. Smart street lighting management. Energy Efficiency. 2013; 6: pp. 609-616.

[15] Long S, Qin R, Elmore C, Ryan T, Schmidt S. LED Roadway Luminaires Evaluation (TRyy1101). Research Report. Missouri Department of Transportation, 2011. https:// library.modot.mo.gov/rdt/reports/tryy1101/cmr12011tryy1101.pdf

[16] U.S. Environmental Protection Agency and Department of Energy. Carbon Dioxide Emissions from the Generation of Electric Power in the United States. Washington D.C.; U.S. Environmental Protection Agency/U.S. Department of Energy 2000. 
